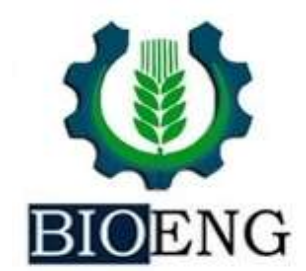

\title{
PRODUÇÃO, QUALIDADE E MATURAÇÃO DA UVA 'SYRAH' EM CONDIÇÃO SUBTROPICAL DO BRASIL
}

\author{
A. Pimentel Junior ${ }^{*}$, F. J. Domingues Neto, \\ M. J. R. Da Silva, M. A. Tecchio
}

UNESP - Universidade Estadual Paulista, Faculdade de Ciências Agronômicas (FCA), Botucatu, São Paulo, Brasil.

Article history: Received 26 November 2018; Received in revised form 21 March 2019; Accepted 22 March 2019; Available online 30 March 2019

\section{RESUMO}

Diante a perspectiva de revitalização da vitivinicultura no Brasil, algumas restrições diante os produtores foram constatadas, sendo, a falta de conhecimento das cultivares de uvas para suco e vinho e seu comportamento nas condições climáticas regionais. Neste sentido, o objetivo do trabalho foi avaliar a produção, qualidade de frutos e a maturação da uva 'Syrah' em região subtropical. O experimento foi realizado na Fazenda Experimental da Unesp, em São ManuelSP. Foi utilizado o delineamento inteiramente casualizados com cinco repetições de cinco plantas cada. As videiras da cultivar Syrah enxertadas no porta-enxerto 'IAC 766' se apresentavam em terceiro ano de produção, no espaçamento de $2,0 \times 0,80 \mathrm{~m}$ e sustentadas sobre o sistema de espaldeira alta. A partir do início da maturação se estendendo até a colheita, foram coletadas semanalmente 100 bagas por parcela experimental para a avaliação da maturação, determinando-se os teores de sólidos solúveis (SS), acidez titulável (AT), pH e relação SS/AT. Por ocasião da colheita, avaliou-se: produção, produtividade, número de cachos por planta, massa fresca, comprimento e largura dos cachos, bagas e engaço e número de bagas por cacho. As características de produção, físicas e de maturação da uva 'Syrah', permite considerar que esta cultivar, nas condições subtropicais brasileiras, apresenta condições ideais de produção para elaboração de vinhos.

Palavras-chave: Vitis vinifera, vinho, ácidos orgânicos, qualidade para elaboração de vinho.

\section{PRODUCTION, QUALITY AND MATURITY GRAPE 'Syrah' IN CONDITION SUBTROPICAL OF BRASIL}

\begin{abstract}
Faced with the prospect of revitalizing the wine industry in Brazil, some restrictions on the producers were found, and the lack of knowledge of grape varieties for juice and wine and their behavior in the regional climatic conditions. In this sense, the objective of this study was to evaluate the production, fruit quality and ripeness of the grape 'Syrah' in subtropical region. The experiment was conducted at the Experimental Farm of UNESP in Sao Manuel-SP. The experimental design consisted entirely randomized with five replicates of five plants each. The vines of Syrah grafted on rootstock 'IAC 766' is presented in the third year of production, spacing of $2.0 \times 0.80 \mathrm{~m}$ and sustained on high trellis system. From the beginning of maturity extending to harvest, they were collected weekly 100 berries per experimental plot for assessing the maturity, determining the content of soluble solids (SS), titratable acidity (AT), $\mathrm{pH}$ and SS / AT . At harvest, were evaluated: production, productivity, number of bunches per plant, fresh weight, length and width of clusters, berries and rachis and number of berries per
\end{abstract}

adilson_pimentel@outlook.com 
cluster. The characteristics of production, physical and grape maturation 'Syrah', to suggest that this cultivar, in subtropical Brazilian conditions, provides ideal conditions for the production of winemaking.

Keywords: Vitis vinifera, wine, organic acids, for quality winemaking.

\section{INTRODUÇÃO}

Apesar dos países Europeus, França, Itália e Espanha, ainda possuírem as maiores áreas plantadas de uvas e serem os maiores produtores mundiais de vinho, o panorama da vitivinicultura mundial está em constante mudança, dados da International Organization of Vine and Wine (2013) têm mostrado uma queda na produção desses países tradicionais. Em contrapartida tem-se registrado aumentos na produção de países como China, Nova Zelândia, África do Sul, Chile, Argentina e Brasil os chamados países do "novo mundo vitícola".

Em função da diversidade ambiental no Brasil, existem polos vitícolas típicos de regiões temperadas, subtropicais e tropicais. Regiões subtropicais são aquelas onde a videira é cultivada com um ou dois ciclos anuais, definidos em função de um período de temperaturas mais baixas, nos quais há risco de geadas (PROTAS, 2008). Em 2016 a produção total de uvas no Brasil foi de 1.388.859 toneladas, o Estado de São Paulo produziu 158.781 toneladas da fruta, ocupando a terceira posição no contexto nacional (AGRIANUAL, 2017), de toda produção, apenas $0,4 \%$ são de cultivares destinadas à elaboração de vinho ou suco. Diante a perspectiva de revitalização da vitivinicultura, algumas restrições diante os produtores foram constatadas, dentre as quais, a falta de melhor conhecimento das cultivares de uvas para vinho e seu comportamento nas condições climáticas regionais (SILVA et al., 2008).

\section{MATERIAL E MÉTODOS}

O experimento foi realizado em um vinhedo da Fazenda Experimental do Departamento de Horticultura, pertencente à Faculdade de Ciências
Cultivada há vários séculos na França, a uva 'Syrah' (Vitis vinifera) é, no entanto, de maior importância para a vitivinicultura do novo mundo do vinho, principalmente na Austrália, onde é conhecida como 'Hermitage', e na África do Sul onde é denominada 'Schiraz'. Na região sudeste do Brasil, tem se destacado entre as cultivares na elaboração de vinhos tintos, ainda que os estudos sejam muito recentes para definições sólidas. Suas plantas apresentam bom vigor, produção regular, sofrendo com as podridões dos cachos. Produz vinhos tintos frutados de excelente qualidade, para consumo quando jovens ou mesmo com envelhecimento (SOUZA \& MARTINS, 2002).

O conhecimento da produção, qualidade e da maturação de videiras, principalmente as destinadas à vinificação, é de grande importância para os viticultores, pois através disso, podem fazer a escolha correta da melhor cultivar a ser produzida em determinadas regiões vitícolas e terem conhecimento da época de colheita. Por se tratar de uma cultivar em ascensão, são poucos consistentes os resultados apresentados na literatura referente à uva 'Syrah', promissora na vitivinicultura. Contudo, o objetivo do trabalho foi avaliar a produção, a qualidade físico-química dos frutos e a maturação da uva 'Syrah' em região subtropical brasileira, a fim de indicação para viabilização de uma produção comercial.

Agronômicas/UNESP, em São Manuel-SP $\left(22^{\circ} 25^{\prime} \mathrm{S}\right.$ e $48^{\circ} 20^{\prime} \mathrm{O}$ e altitude de $\left.700 \mathrm{~m}\right)$ no período de 13 de agosto de 2015, com a realização da poda curta, à 06 de janeiro de 
2016, quando se deu a colheita. O clima da região, segundo a classificação de Köppen é Cwa, região subtropical, com temperatura média mínima anual de $14,5^{\circ} \mathrm{C}$ e máxima de $27,1^{\circ} \mathrm{C}$, o acúmulo anual médio pluviométrico é de $1.464,8$ mm (CEPAGRI, 2018). O solo da unidade experimental é classificado como Latossolo Vermelho Amarelo distrófico (PRADO, 2003).

O delineamento experimental utilizado foi inteiramente casualizados com cinco repetições de cinco plantas cada. As videiras da cultivar Syrah enxertadas no porta-enxerto 'IAC 766' se apresentavam em terceiro ano de produção, no espaçamento de $2,0 \times 0,80 \mathrm{~m}$ e sustentadas sobre o sistema de espaldeira alta, com arames dispostos a 1,0;1,3; 1,5 e 1,8 m acima do nível do solo. No estádio de mudança de cor das bagas, a área experimental foi protegida com telas antigranizo (18\% de sombreamento), para proteção contra chuvas de granizo, ataque de pássaros e abelhas. Após a poda de produção foi aplicado calciocianamida hidrogenada a 5\% para indução e uniformidade da brotação. O sistema de irrigação utilizado na área experimental foi o de gotejo.

A partir do início da maturação até a colheita foi avaliada através mosto a maturação da uva 'Syrah', em coletas semanais de 100 bagas por parcela experimental. $\mathrm{O}$ mosto foi obtido por meio de trituração das bagas com auxílio de mixer. Foram determinados os teores de sólidos solúveis (SS), por refratometria direta, através de refratômetro digital Atago ${ }^{\circledR}$, expresso em ${ }^{\circ}$ Brix; acidez titulável (AT), determinada por volumetria potenciométrica, titulando-se solução de hidróxido de sódio $(0,1 \mathrm{~N})$, expressa em $\mathrm{g}$ de ácido tartárico $100 \mathrm{~g}^{-1}$ de polpa; relação SS/AT; e pH, utilizando pHmetro Micronal B-274. Essas análises foram feitas

\section{RESULTADOS E DISCUSSÃO}

A média de massa fresca dos cachos da uva 'Syrah' foi de 126,58 g e o comprimento e largura de 11,98 e 6,21 cm, conforme metodologia do Instituto Adolfo Lutz (BRASIL, 2008).

Por ocasião da colheita, determinado com a estabilização do teor de sólidos solúveis e acompanhando-se os valores de acidez, característico da cultivar, todos os cachos de cada parcela foram pesados e o valor obtido foi divido pelo número de plantas, determinando-se assim a produção média por planta, expressa em $\mathrm{kg} \mathrm{pl}^{-1}$; para a produtividade, multiplicou-se a produção média por planta de cada parcela pelo número de plantas por hectare, sendo o resultado expresso em $\mathrm{t} \mathrm{ha}^{-1} \mathrm{e}$ o número de cachos por planta adquirido através a multiplicação entre o número total de cachos pelo número de plantas, expresso como cachos $\mathrm{pl}^{-1}$.

Em amostragem de 10 cachos por parcela experimental, foram determinadas as massas frescas (MF) de cacho e engaço, através de pesagem em balança analítica com precisão de $0,1 \mathrm{~g}$, e os resultados expressos em g; comprimento (C) e largura (L) de cachos e engaços, com auxílio de régua graduada, expressos em $\mathrm{cm}$; e o número de bagas por cacho (NBC). De cada cacho amostrado, foram retiradas 10 bagas, totalizando 100 bagas por parcela experimental, para determinação da massa fresca, comprimento e largura de bagas, sendo a massa obtida pela pesagem em balança analítica, e os resultados expressos em $\mathrm{g}$, e as dimensões, com auxílio de régua graduada em $\mathrm{mm}$.

Os resultados obtidos foram submetidos à análise de Estatística Descritiva para as características físicas dos cachos e de produção e análise de variância (Teste F) com posterior regressão polinomial para expressar a evolução da maturação através das características químicas do mosto com o programa computacional SISVAR (FERREIRA, 2011).

respectivamente (Tabela 1). Também em condições subtropicais estudando a cultivar 'Syrah', Silva (2015) verificou o peso e 
dimensões semelhantes, sendo $120,8 \mathrm{~g}$ para a massa fresca, $11,18 \mathrm{~cm}$ de comprimento e $5,90 \mathrm{~cm}$ de largura dos cachos, sobre o mesmo porta-enxerto e sistema de condução. Dias et al. (2012), também avaliando a mesma cultivar, 'Syrah', constataram valores superiores na massa dos cachos, na ordem de 217,23 g na safra de 2010 sob as mesmas condições climáticas, porém Favero et al. (2008) observou mesma área estudada, nos anos de 2005 e 2006, valores compatíveis com o presente trabalho, entre 111,15 e 142,56 g, entende-se que um vinhedo com plantas mais antigas de 'Syrah' a massa dos cachos e o potencial produtivo tende a aumentar.

O valor de massa das bagas foi de $2,19 \mathrm{~g}$ com um comprimento e largura de 1,48 e $14,86 \mathrm{~mm}$, respectivamente. Silva (2015) notou características das bagas semelhantes em mesmas condições climáticas com a uva 'Syrah'. Para elaboração de vinhos tintos, o tamanho das bagas é um fator que determina a qualidade da uva, depende principalmente das características genéticas da cultivar, pois, nas bagas menores, há maior relação entre soluto e solvente e, consequentemente, maior probabilidade de extração de compostos presentes na casca durante o maceramento (CONDE et al., 2007).

O número de bagas por cacho foi de 54,64, média semelhante aos dados encontrado por Silva (2015) e discrepantes aos resultados de Dias et al. (2012) que obtiveram 185 bagas por cacho, aproximadamente 130 bagas a mais, em plantas no $7^{\circ}$ ano de produção de uvas 'Syrah'. Sebastian et al. (2015), em região mediterrânea concluíram que a cultivar 'Syrah', quando irrigadas racionalmente, apresentam 171,7 bagas por cacho.

O engaço apresentou massa de 7,74 g, comprimento de $9,35 \mathrm{~cm}$ e largura de $4,09 \mathrm{~cm}$, as médias confirmam os resultados observados por Silva (2015) com a mesma cultivar. A respeito das características de engaços de uvas para vinho, são escassos os trabalhos encontrados na literatura, atribuindo seu peso e dimensões apenas ao rendimento de uvas para o processamento.

A produção, produtividade e número de cachos foi de, respectivamente, $1,45 \mathrm{~kg}$ $\mathrm{pl}^{-1}, 9,04 \mathrm{t} \mathrm{ha}^{-1}$ e 12,50 cachos $\mathrm{pl}^{-1}$. Os valores são considerados baixos quando comparado com outros autores que estudaram a uva 'Syrah', como Dias et al. (2012) e Sebastian et al. (2015), que alcançaram aproximadamente $3,9 \mathrm{~kg} \mathrm{pl}^{-1}$,

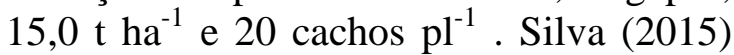
obteve valores ainda menores para essa cultivar, sendo $0,59 \mathrm{~kg} \mathrm{pl}^{-1}, 2,35 \mathrm{t} \mathrm{ha}^{-1} \mathrm{e}$ 3,74 cachos por planta, em região subtropical. Além da influência das condições climáticas do ano de cultivo, a incidência de pragas e/ou doenças sobre os cachos e folhas, afeta diretamente a produção das videiras e o porta-enxerto também exerce função importante na produção, sendo que o 'IAC 766' apresenta ótimas condições de compatibilidade, uma vez que esta cultivar foi desenvolvida em território nacional e apresenta ótima adaptação e médio vigor (PIMENTE JUNIOR et al., 2018).

A evolução do teor de sólidos solúveis (SS), estimado pela equação de regressão polinomial, apresentou um efeito quadrático positivo, variando no início da maturação, considerado quando $50 \%$ das bagas mudaram de cor, de $9,98{ }^{\circ}$ Brix a $15,42^{\circ}$ Brix, na maturação, ou seja, houve um aumento médio de $0,1648{ }^{\circ}$ Brix de SS/dia (Figura 1A). No início da maturação, o teor de SS foi influenciado pelo alto teor de ácidos orgânicos presentes na baga e com a evolução da maturação, a atuação desses ácidos tornou-se reduzida, e a dos açúcares, maior, em implicação da degradação dos ácidos tartárico e málico e do aumento, pela folha, da síntese de sacarose (MANFROI et al., 2004). 
Tabela 1. Massa fresca (MF), comprimento (C) e largura (L) do cacho, da baga e do engaço, número de bagas cacho $^{-1}$ (NBC), produção, produtividade e número de cachos por planta da uva 'Syrah' cultivada em região subtropical. UNESP/FCA, São Manuel-SP, 2015/2016.

\begin{tabular}{|c|c|c|c|c|c|c|c|}
\hline \multirow{2}{*}{$\begin{array}{l}\text { Estatística } \\
\text { Descritiva }\end{array}$} & \multicolumn{3}{|c|}{ Cacho } & \multicolumn{3}{|c|}{ Baga } & \multirow[t]{2}{*}{$\mathrm{NBC}$} \\
\hline & $\mathrm{MF}(\mathrm{g})$ & $\mathrm{C}(\mathrm{cm})$ & $\mathrm{L}(\mathrm{cm})$ & MF (g) & $\mathrm{C}(\mathrm{mm})$ & $\mathrm{L}(\mathrm{mm})$ & \\
\hline Média & 126,58 & 11,98 & 6,21 & 2,19 & 16,48 & 14,86 & 54,64 \\
\hline Erro padrão & 8,03 & 0,47 & 0,22 & 0,04 & 0,13 & 0,11 & 3,55 \\
\hline Desvio padrão & 39,32 & 2,31 & 1,06 & 0,20 & 0,64 & 0,52 & 17,41 \\
\hline Mínimo & 62,00 & 7,50 & 5,00 & 1,92 & 15,50 & 14,00 & 26,44 \\
\hline Máximo & 196,00 & 17,00 & 9,50 & 2,70 & 18,20 & 16,00 & 90,93 \\
\hline $\mathrm{CV} \%$ & 31,06 & 19,32 & 17,11 & 9,32 & 3,89 & 3,52 & 31,87 \\
\hline \multirow{2}{*}{$\begin{array}{l}\text { Estatística } \\
\text { Descritiva }\end{array}$} & \multicolumn{3}{|c|}{ Engaço } & Produção & \multirow{2}{*}{\multicolumn{2}{|c|}{$\begin{array}{l}\text { Produtividade } \\
\left(\mathrm{t} \mathrm{ha}^{-1}\right)\end{array}$}} & \multirow{2}{*}{ Cachos $\mathrm{pl}^{-1}$} \\
\hline & $\mathrm{MF}(\mathrm{g})$ & $\mathrm{C}(\mathrm{cm})$ & $\mathrm{L}(\mathrm{cm})$ & $\left(\mathrm{kg} \mathrm{pl}^{-1}\right)$ & & & \\
\hline Média & 7,74 & 9,35 & 4,09 & 1,45 & \multicolumn{2}{|c|}{9,04} & 12,50 \\
\hline Erro padrão & 0,51 & 0,41 & 0,21 & 0,24 & \multicolumn{2}{|c|}{1,49} & 1,75 \\
\hline Desvio padrão & 2,49 & 1,99 & 1,04 & 0,53 & \multicolumn{2}{|c|}{3,33} & 3,91 \\
\hline Mínimo & 3,55 & 6,00 & 3,00 & 0,78 & \multicolumn{2}{|c|}{4,85} & 7,00 \\
\hline Máximo & 12,77 & 14,00 & 7,50 & 2,03 & \multicolumn{2}{|c|}{12,68} & 17,00 \\
\hline $\mathrm{CV} \%$ & 32,16 & 21,29 & 25,42 & 36,81 & \multicolumn{2}{|c|}{36,81} & 31,24 \\
\hline
\end{tabular}
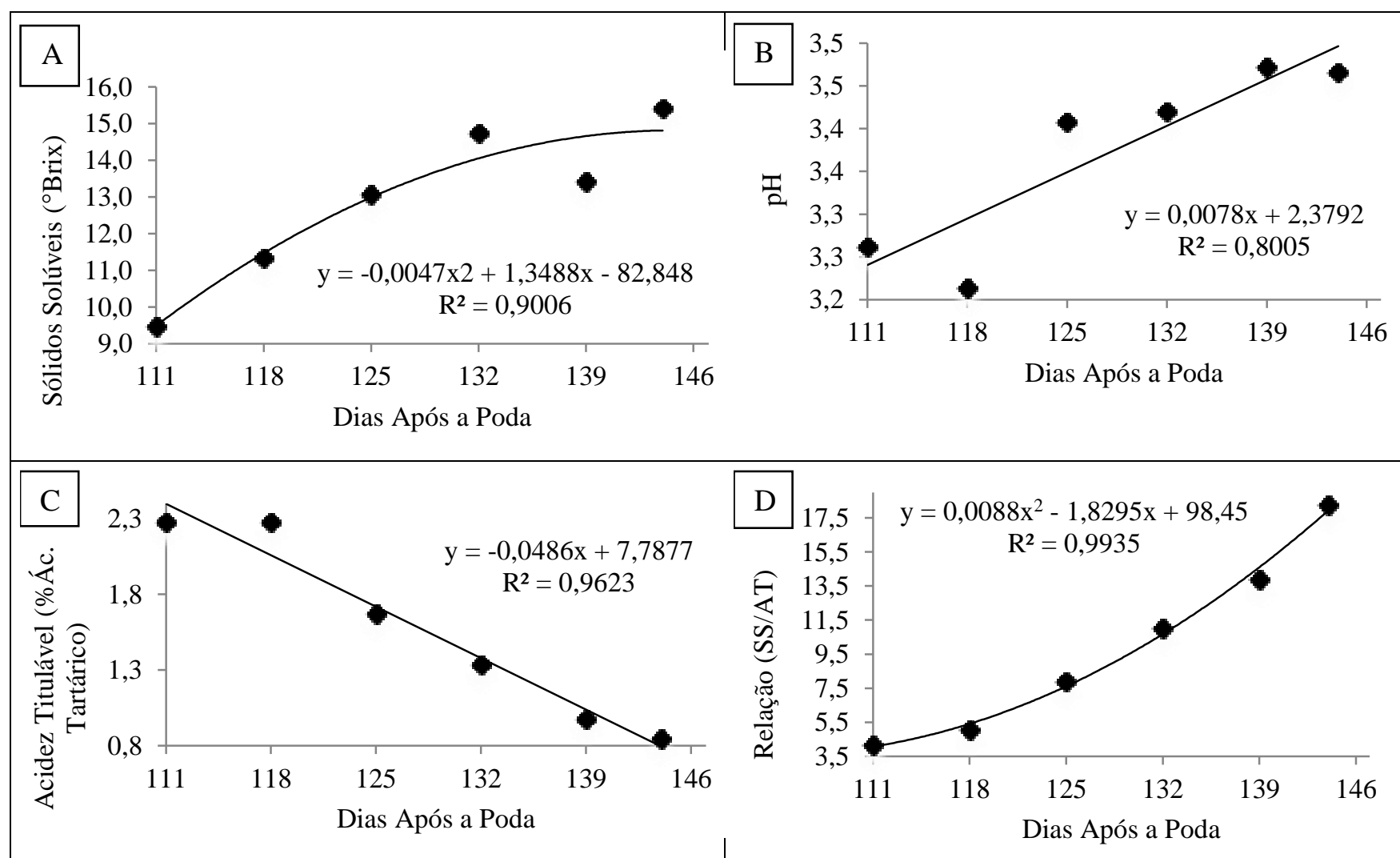

Figura 1. Atributos de maturação da uva 'Syrah': (A): Sólidos solúveis (SS), (B): pH, (C): acidez titulável (AT) e (D): Relação SS/AT. UNESP/FCA, São Manuel-SP, 2015/2016.

Os resultados obtidos na colheita não apresentaram valores de SS adequados para a produção de vinhos de qualidade, que segundo GRIS et al. (2010) ficam entre 19,0 e $25,0{ }^{\circ}$ Brix, independente da cultivar utilizada. Isso é explicado pela colheita ter coincidido com o período chuvoso da região, o que ocasionou na 
diluição dos SS. Quando a colheita de uvas ocorre em períodos de excesso hídrico e altas temperaturas diurnas e noturnas em condições subtropicais, o teor de SS e a qualidade dessas uvas são prejudicadas (COOMBE, 1992; HERNANDES et al., 2010; DIAS et al., 2012).

$\mathrm{O}$ pH demonstrou um efeito linear diante os dias após a poda (Figura 1B), partindo do ponto mínimo de 3,39 para 3,80 , diferença de 0,41 até a colheita da uva. Fraige et al. (2015) também encontraram esta evolução de $\mathrm{pH}$ para a uva 'Syrah'. O aumento do $\mathrm{pH}$ é dependente da acidez total da uva, mas também das concentrações relativas de ácidos málico e tartárico e do grau de formação de sais ácidos como o cátion potássio, apresentando uma evolução inversa a acidez (MANFROI et al., 2004; MOTA et al., 2010). Valores de pH abaixo de 3,30 em mosto das uvas, não são recomendáveis para vinificação, pois interfere negativamente na qualidade do vinho (RIZZON \& MIELE, 2002). Os valores encontrados neste estudo estão dentro do recomendado, segundo estes autores para uvas em geral.

\section{CONCLUSÕES}

As características médias físicas, químicas e a maturação observada para a uva 'Syrah' permitem considerar que esta

\section{REFERÊNCIAS BIBLIOGRÁFICAS}

\section{ANUÁRIO DA AGRICULTURA BRASILEIRA, AGRIANUAL. Uva: produção brasileira, São Paulo, p. 464, 2017.}

BRASIL. Ministério da Saúde. Agência Nacional de Vigilância Sanitária. Métodos

físico-químicos para análise de alimentos. Brasília, 1018 p. 2005.

BLOUIN, J.; GUIMBERTEAU, G. Maturation et maturité des raisins. Bordeaux: Féret, 151p. 2000.

CENTRO DE PESQUISAS METEOROLÓGICAS E CLIMÁTICAS APLICADAS A AGRICULTURA
A acidez titulável (AT) decresceu linearmente durante a maturação da uva 'Syrah', apresentando uma diferença de $1,43 \%$ do início da maturação até a colheita (Figura 1C). A diminuição da concentração da AT é devida à diluição do mosto pelo aumento de volume do fruto, transportada no xilema pela mobilização de bases que neutralizam os ácidos orgânicos e pelo processo respiratório que demanda por energia (RIZZON et al., 2000; BLOUIN \& GUIMBERTEAU, 2000). O valor da AT obtido na colheita no presente trabalho foi semelhante aos relatados por Santos et al. (2011b), Fraige et al. (2015) e Silva (2015) para a cultivar 'Syrah', a mesma em estudo, em região subtropical.

Efeito quadrático crescente foi obtido para a relação SS/AT (Figura 1D), com ponto máximo de 25,15 , que encontram-se dentro do exigido pela legislação brasileira (relação SS/AT entre 15 e 45). Esta relação pode indicar o equilíbrio ideal entre açúcar e acidez que pode caracterizar a maturação de cultivares numa determinada região. No entanto, deve-se ter atenção na utilização desse índice de maturação, pois aumentos na concentração de SS nem sempre retribuem à igual redução da AT.

uva, nas regiões subtropicais brasileiras, apresenta condições médias ideais para a produção e elaboração de vinhos.

(CEPAGRI). Clima dos Municípios Paulistas: Disponível em: $<$ http://www.cpa.unicamp.br/outrasinformacoes/clima-dos-municipiospaulistas.html>. Acesso em: 01 de ago. de 2018.

CONDE, C., SILVA, P., FONTES, N., DIAS, A. C. P., TAVARES, R. M., SOUSA, M. J., AGASSE, A., DELROT, S., GERÓS, H. Biochemical changes throughout grape berry development and fruit and wine quality. Food, Amsterdam, v. 1, p. 1-22, 2007. 
COOMBE, B. G. Research on development and ripening of the grape berry. American Journal of Enology and Viticulture, v.43, n. 1, p. 101-110, 1992. DIAS, F. A. N., MOTA, R. V., FÁVERO, C. A., PURGATTO, E., SHIGA, T. M., SOUZA, C. R., PIMENTEL, R. M. A., REGINA, M. A. Videira 'Syrah' sobre diferentes porta-enxertos em ciclo de inverno no sul de Minas Gerais. Pesquisa Agropecuária Brasileira, Brasília, v. 47, n. 2, p. 208-215, 2012.

FAVERO, A. C., AMORIM, D. A., MOTA R.V., SOARES, A.M., REGINA, M.A. Viabilidade de produção da videira 'Syrah', em ciclo de outono inverno, na região Sul de Minas Gerais. Revista Brasileira de Fruticultura, Jaboticabal SP, v. 30, n. 3, p. 685-690, 2008.

FERREIRA, D. F. Sisvar: a computer statistical analysis system. Ciência e Agrotecnologia, Lavras, v. 35, n. 6, p. 1039-1042, 2011. $\begin{array}{llr}\text { FRAIGE, } & \text { K., } & \text { GONZÁLEZ- } \\ \text { FERNÁNDEZ, } & \text { R., } & \text { CARRILHO, E., }\end{array}$ JORRÍN-NOVO, J. V. Metabolite and proteome changes during the ripening of 'Syrah' and 'Cabernet Sauvignon' grape varieties cultured in a nontraditional wine region in Brazil. Journal of Proteomics, v. 113, n.1, p.206-225, 2015.

GRIS, E. F.; BURIN, V. M.; BRIGHENTI, E.; VIEIRA, H.; BORDIGNON-LUZ, M. T. Phenology and ripening of Vitis vinifera L. grape varieties in São Joaquim, southern Brazil: a new South American wine growing region. Investigación Agraria, v. 37, n. 2, p. 61-75, 2010.

HERNANDES, J. L., PEDRO JÚNIOR, M. J., SANTOS, A. O., TECCHIO, M. A. Fenologia e produção de cultivares americanas e híbridas de uvas para vinho, em Jundiaí-SP. Revista Brasileira de Fruticultura, Jaboticabal, v. 32, n. 1, p. 135-142, 2010.

IAL, Instituto Adolfo Lutz (São Paulo). Métodos físico-químicos para análise de alimentos /coordenadores Odair Zenebon, Neus Sadocco Pascuet e Paulo Tiglea -São Paulo: Instituto Adolfo Lutz, p. 1020 versão eletrônica. 2008.
INTERNATIONAL ORGANIZATION OF VINE AND WINE. Statistical report of world vitiviniculture. Paris, 28 p. 2013. MANFROI, L.; MIELE, L.; RIZZON, L. A.; BARRADAS, C. I. N.; SOUZA, P. V. D. Evolução da maturação da uva 'Cabernet Franc' conduzida no sistema lira aberta. Ciência e Agrotecnologia, Lavras, v. 28, n. 2, p. 306-313, 2004.

MOTA, R. V.; SILVA, C. P. C.; FAVERO, A. C.; PURGATTO, E.; SHIGA, T. M.; REGINA, M. A. Composição físico-química de uvas para vinho fino em ciclos de verão e inverno. Revista Brasileira de Fruticultura, Jaboticabal, v. 32, n. 4, p. 1127-1137, 2010.

PIMENTEL JUNIOR, A., DOMINGUES NETO, F. J., DA SILVA, M. J. R., PAIVA, A. P. M., VEDOATO, B. T. F., SIMONETTI, L. M., TECCHIO, M. A. Development of rootstocks grapevine and cold stratification time. Australian Journal of Crop Science, v. 12, n. 7, p. 1058, 2018.

PROTAS, J. F. S. A produção de vinhos finos: um flash do desafio brasileiro. Agropecuária Catarinense, Santa Catarina, v. 21, n. 1, p. 17-19, 2008.

RIZZON, L. A.; MIELE, A. Avaliação da cv. Cabernet Sauvignon para elaboração de vinho tinto. Ciência e Tecnologia de Alimentos, Campinas, v. 22, n. 2, p. 192198, 2002.

RIZZON, L. A.; MIELE, A.; MENEGUZZO, J. Avaliação da uva cv. Isabel para elaboração de vinho tinto. Ciência e Tecnologia de Alimentos, Campinas, v. 20, n. 1, p. 115- 121, 2000.

SANTOS, A. O.; HERNANDES, J. L.; PEDRO JÚNIOR, M. J.; ROLIM, G. S. Parâmetros fitotécnicos e condições microclimáticas para videira vinífera conduzida sob dupla poda sequencial. Revista Brasileira de Engenharia Agrícola e Ambiental, v.15, p.1251-1256, 2011.

SEBASTIAN, B.; BAEZA, P.; SANTESTEBA, L. G.; MIGUEL, P. S.; LA FUENTE, M.; LISSARRAGUE, J. R. Response of grapevine cv. Syrah to irrigation frequency and water distribution 
pattern in a clay soil. Agricultural Water Management. v.148, n.1, p. 269-279, 2015.

SILVA, P. R.; OJIMA, A. L. R.; FRANCISCO, V. L. S.; VERDI, A. R.; BAPTISTELLA, C. S. L. Diagnóstico produtivo, tecnológico e gerencial da vitivinicultura no estado de São Paulo. Informações Econômicas, São Paulo, v. 38, n. 4, p. 31-51, 2008.
SOUSA, J. S. I.; MARTINS, F. P. Viticultura brasileira: principais variedades e suas características. Piracicaba: FEALQ, 368 p. 2002.

SILVA, M. J. R. Porta-enxertos na produção e nas características físicoquímicas da uva e do vinho de diferentes cultivares em Jundiaí, SP. $100 \mathrm{f}$. Dissertação (Mestrado)-Universidade Estadual Paulista "Júlio de Mesquita Filho", Botucatu, 2015. 